\title{
Identifying and Explaining Some Structural Asymmetries in Kurdish vs. the English Language: Morphological and Syntactic Typology Study
}

\author{
Areen Ahmed Muhammed ${ }^{1,2}$ \\ ${ }^{1}$ School of Foreign Languages, Central China Normal University, Wuhan, China \\ ${ }^{2}$ English Department, Charmo University, As-Sulaymaniyah, Kurdistan
}

Email address:

hibalboa@yahoo.com

\section{To cite this article:}

Areen Ahmed Muhammed. Identifying and Explaining Some Structural Asymmetries in Kurdish vs. the English Language: Morphological and Syntactic Typology Study. English Language, Literature \& Culture. Vol. 2, No. 6, 2017, pp. 115-123. doi: 10.11648/j.ellc.20170206.14

Received: October 19, 2017; Accepted: November 28, 2017; Published: January 2, 2018

\begin{abstract}
Language is a framework that human can participate and share their ideas together. Using different languages created wide ranges of cultures and traditions. In this paper relations between two languages (English and Kurdish) will be explained in term of typology. Linguistic typology is 'the classification of languages according to their general structure rather than according to their historical or geographical relationship'. It aims at putting forward hypotheses concerning universal characteristics of underlying syntactic categories and structures for both languages, and interrelations between them in one dimension; and identifying their differences morphologically would be another pole. The main objective of the paper serves second language learners of any of two languages do not use their mother tongue structure in speaking target languages; however, understanding the main syntax and morphology of the target language will be more helpful and useful to cope with the learned language easier and faster. The paper brings different pieces of evidence concerning Morphology and Syntax for both languages and each will be illustrated in detail. Later, logical answers will be given to research questions. In the morphological section, different parameters, free and boundary morphemes, and inflectional and derivational morphemes of both languages will be explained by comparing and contrasting each other in both languages. Additionally, in regard to Syntactic variations, word order asymmetries will be identified. Moreover, inside the sections, parameters of both languages` word formations will be analyzed, the effect of intonation on sentence meaning will be explained, helpful tips will be given to learning language however their word orders are different, and finally, the universality of both languages will be proved. Then, a conclusion will sum up the paper in a nutshell.
\end{abstract}

Keywords: Morphology, Syntax, Semantics, Kurdish Language, Asymmetry, Language Typology

\section{Introduction}

Recently, increased interests of different Typological researchers have been seen. Moreover, it is relatively a new science as it emerged to the branch of linguistics in the second half of 20s century. Typology (Empirical Scientific Research, ESR) is the study of cross-linguistic variations and diversities; it investigates different attempts of grammatical trends in human's language and how they are bonded together (Comrie, 1981 and Plank, 2007) and has different uses in both language and linguistics. In this paper, mainly, Morphological and Syntactic typological perspectives on both Kurdish and English will be provided, to situate the different typological knowledge of both languages.

The objective of the paper is to declare structural differences between Kurdish and English language through Morphological and syntactical typology or to peel off the problems and help 2LL (Second Language Learners) comprehend the Kurdish language much easier based on some systematic rules. Additionally, the paper will identify some problems in learning Kurdish language and later suggest some fundamental methods and principles acquire the language faster and easier as its yet unsettled because the Kurdish Language is somehow considered as a deprived 
language from other languages and does not follow certain universal rules of language. Moreover, the assignment will answer a few research questions to help learners learn the language without using his/her native grammar (Idea Transformation):

a. Morphologically, Crucial Issue, what parameters are used in English and Kurdish language word formation?

b. Does intonation affect the sentence structure and its meaning? In the Kurdish Language specifically.

c. How is Basic word order of Kurdish different from English Syntactically?

d. The absence of Standard Average to compare English and Kurdish in cross-linguistic comparability; then, does the Kurdish language undergo the category of universality?

\section{Language Universals and Linguistic Typology: General Overview}

Language is the most important source of communication between the individuals in their daily conversations; still, it is accounted for the most mysterious behaviour which is possessed to human only (Russell, 1948). Consequently, human's capacity to learn another language (s) is another debatable issue among scholars and scientists (Whaley, 2008). According to different studies, there is a general estimation for world language which easily shoots 7000; this huge amount of diversity comes from a basic word order. In his source, Whaley (2008: 7) illustrated typology as "the classification of different components of language based on shared formal characteristics". Additionally, based on past experiences and resources of linguists, language is like a puzzle however they are different on some issues but still, there are similarities between them. The similarities and differences between languages deal with Distribution of Structural Properties, which means it does not deal with where and how they occur? Whilst, the reason for their similarities and differences concerned with why and when it does?

This section deals with different linguistic typology to learn how languages are different, and to find out some variables regarding cross-linguistic variations; unlike Binding Theory which is designed to show how languages work. Moreover, historical and contact linguists are looking for some similarities between different languages; since those similarities can be inherited and spread through communications. Different typologists are looking for different variables and are interested in different crosslinguistic variations to extend the limitation of the ideas. In addition, this type of study shortens the way to arrive at the idea of what the languages have in common.

To be more precise, linguistic typology is the study of language and linguistic diversities, which is "descriptive or taxonomic" (Croft, 1990, 2002: 3, 2003); furthermore, it is rather inductive, in which it studies human language through empirical diversities and examples, and based on diachronic explanations. Additionally, in linguistic typology, there is no language to be taken as the role model (Song, 2011). In case of language, linguistic typology plays a crucial role in the case of SLA (Second Language Acquisition) and critical period; since the person`s poor linguistics`experiences may not prepare him/her for such infinite diversity. Moreover, sometimes the person passes through difficult periods, let it be a different word-order language.

The traditional partition of different languages' division, fusion and polysynthetic became tremendously helpful typology for many linguists. As this study (typology) does not only defer distinct variables but does offer systems that help our language knowledge. Typology is more like the classification of different structural types and study on different systematic patterns across languages; it deals with cross-linguistic comparisons (Croft, 2002, 2003). In his source, Jung (2001) explained that typological analysis should undergo several processes as (I) Identification of the phenomenon to be studied. (II) Typological classifications should be investigated. (III) The formulation of the generalization over the classification should be accounted for. And finally, (IV) The explanation of the generalization should be illustrated.

Simply speaking, the study of universals is concerned with what human languages have in common, while the study of typology deals with ways in which languages differ from each other. This contrast, however it is not precise, will appear when languages differ from each other in terms of the variations and it is not arbitrary but has boundaries. In addition, linguistic typology is not only alarmed with variations, but also with the limitations on the degree of variation found in different languages of the world. It is due to these limitations that languages may be meaningfully divided into various types.

Different issues and problems may appear when two languages are somehow different. In case of Kurdish language, not too many people can learn the language easily is due to its complex grammatical structure and its wordorder formation processes. The issue will be analyzed more precisely in morphological and syntactical typology which will be the later section. Haegeman (1994) described the relations between the generative grammar of languages and then later he specified his approach to cross-linguistic variation. Hence, universal grammar is no longer sets of universal rules but it is a specific set of principles with different parameters (in a broader idea, it is more like a crosslinguistic typology). Shortly, despite the differences between the two languages (English and Kurdish), there are some properties whereby the language (Kurdish) falls into the category of human language. Moreover, such unity between the languages created linguistic typology.

In summary, linguistic typology is a set of different parameters and philosophies; different philosophies will be born and vanishes till the exact interpretation will be available. Moreover, there is no single system to force all the languages to go on a specific path; therefore, data and experiments are the only evidence that linguists rely on. 


\section{Morphological and Syntactic Typology}

In this section, two main domains of typology will be studied. Morphological: the study of the formal and semantic composition of individual words. And, Syntactic: the relation of the words in a sentence. It is believed that the relationship between the word order and order of affixes in different languages became the source of debate among linguists and typologists; under this shade, morphological typology is directly associated with syntax; which means, particular affix order works with the particular syntactic order. Hence, the study will be applied to both English and Kurdish and will support the idea of Universality for English and Randomness, to some extent, of the Kurdish language.

\subsection{Cross-Linguistic Morphological Variation: Kurdish vs. English}

\subsubsection{Different Parameters in Morphological Typology}

Since numbers of holistic typologies have been studied, but there are two particular ones, at least from the historical perspectives. Morphological typology is accounted as one of them; it was predominant in late $19 \mathrm{~s}$ and early 20 s century. In the present sub-section, we do not only provide some traditional lore concerning morphological typology but to show differences between both languages to improve the understanding. Furthermore, in discussing morphological typology, 5 parameters are usually mentioned: Affixation, Number of Morpheme per words, Degree of Fusion, Polysynthetic, and Morpho-syntactic Contexts (Sapir, 1921; Poppe, 1960; Fortescue, 1984; and Bybee, 1997). Other sources by Croft (1990, 2002: 46, and 2003) illustrated different types of morphological classification under the shadow of the classical version; as in isolating languages, they do not use affixes at all; agglutinative languages use affixes as a single grammatical category; and inflectional languages use affixes that link different grammatical categories. Respectively, Payne (1997: 27) explained traditional Morphological Typology, and he includes 4 different types: isolating, agglutinative, fusing and polysynthetic. Accurately, Isolating languages, "every word consists of only one morpheme", have no specific rule of morphology; at least ideally, such languages are a one-to-one correspondence between words and morphemes. However, Whaley (2008) rejected the idea and said that there is no such thing as a complete isolating language in the world. Such as These Examples:

Wǒ zài măi shū le. (Mandarin Chinese)

I DUR buy book CRS

"I am buying a book." (Li and Thompson, 1981:21)

Kate hatma mali bradarakam dastmankrda xwendn. (Kurdish)

When come (I) house (his) friend (me) begin (we) (to) study.

When I came to my friend's house, we began to study.

The words in the above examples are invariable, and there is no morphological variation for. In the case of the Kurdish tense, both (come and begin) is used instead of (came and began); similarly, the Chinese case in (buying). On the other hand, the time adverbial of the sentence is the same as the English one. As a support to Payne's (1997) work, Kurdish does not have separate pronouns to indicate the person, it is more like a boundary morpheme and it binds itself to the verb. Another case, the Kurdish language does not use prepositions so frequently, since changing the phonological structure of the sound will change the meaning of the same proposition; as an example:

La mal (falling intonation) ---------- in-house.

La mal (rising intonation) ---------- to the house.

The above examples will show how the language will use different prepositions only through using different intonations. Then, this is one of those difficulties that foreign learners of Kurdish language will face.

Agglutinating languages, having longer word pattern, are consisted of one morpheme; but the word boundaries are always definite (Comrie, 2009). Furthermore, the morpheme has its shape, so it is much easier to identify it. The declaration can be given through a table of examples given in both languages; as the main word stay the same but a boundary morpheme will change its case and number. Happily, this made the case of Kurdish language easier to comprehend in case the learner knows the root word (noun). For instance:

Table 1. Singularity and Plurality of both Languages.

\begin{tabular}{llll}
\hline & English & & Kurdish \\
\cline { 2 - 4 } & Singular & Plural & Singular \\
\hline Nominative & A man & Men & Pyaw-aka \\
Accusative & A man & Men & Pyaw-ek \\
Genitive & Man`s of a & Men`s of a & Pyaw-eki \\
Dative & To a man & To Men & Bo pyaw-aka, bo pyaw-ek \\
Vocative & O'man & O`men & Pyaw- \\
Ablative & With, from, by a man & With, from, by a men & Paw-akan \\
\hline
\end{tabular}

In the contrary, in polysynthetic languages, English is more productive than Kurdish; since the English language combine different lexical morphemes together to formulate one; $($ swim) and (suit) = (swimsuit), as each word of (swim, suit, and swimsuit) gives a different meaning and has an individual stakeholder. But this case is absent in Kurdish as the different lexical morphemes cannot bind together unless you put a boundary morpheme between them (j1) (mala) = (Jl-i-mala). That (i) = ("of" in English) morpheme does not have any meaning in Kurdish when it is used separately; whilst, in term of combination, it should be used to bind simple words together and form a compound word. In both 
cases of singularity or plurality, the same (i) will be used. Or an example like (terrible headache), the case in Kurdish will be like $($ sar + esha $+\mathrm{i}+$ yaki + qurs + leydawm $)====($ head + ache + of + one + hard + hit the body). Such correlation between the words made the language difficult to learn its combinations and to comprehend its morphology (Comrie, 2009).

Fusional type "morphemes that carry more than one meaning" (Lyovin, 1997: 15) is considered as the Fourth type. Surprisingly, neither Kurdish nor English is considered as this type; it can be found in Latin and Dutch languages.

\subsubsection{Free and Boundary Morphemes}

Another case could be Bound and Free morphemes, the Kurdish language is more Danish like indefiniteness, as (the, $a$, and an) are free morphemes in English and they are bound in Danish and Kurdish; as illustrated in the below examples:

a. Danish: Dag (day).... Dagen (the day), Park (park).... Parken (the park), or Vise (song).... Visen (the song). (Whaley, 2008)

b. Kurdish, Definite article: Rozh (day).... Rozhaka (the day), Park (park).... Parkaka (the park), or Gorani (song)... Goraniyaka (the song).

Indefinite article: Rozh (day)... Rozhek (a day), Park (park)... Parkek (a park), or Gorani (song)... Goraniyak (a song).

Such examples will show the tree diagram of the languages and how each language directly or indirectly is related to the language ancestors of its origin.

\subsubsection{Inflectional and Derivational Morphemes}

Derivational and Inflectional Morphemes in English will not change the internal word structure and spell; whilst, in Kurdish, the word passes from one phase to another. For example (Establishments: establish + ment $+\mathrm{s}$ ) and (Damazrawakan: Damazrandn $+\varnothing+$ akan) (the word type will change from \{damazrandn \} as [Verb] to \{damazrawa as [Noun] without any affixes, but only through an internal change of word type).

Such systematic change in the English language helped the people to cope with different words easily just through adding affixes; apart from some unique cases of internal changes; such as foot (singular) to feet (plural). Nevertheless, the case with the Kurdish language is rather a headache since the type of the word, mostly, should undergo an internal change; such as the above examples of (Establishments = Damazrawakan). Accordingly, Derivational morphemes in English create a new pattern and new word; as in (type retype), but in Kurdish, the root remains the same so the meaning of the word remains the same and no new word will be formulated; as in (nusin \{type - nusinawa \{retype\}). That could be an obvious reason why predictability to know the word in Kurdish is much easier than in English (Whaley, 2008). Moreover, Bybee (1985: 123) mentioned that "there is no categorical distinction between inflectional and derivational...but some are on the continuum of inflectional and some on derivational" as the example of (-ing) in ssaying (v.) [Present continuous of "say"] and saying (n.) [Proverb].
Researcher's native language (Kurdish) is a clear-cut prove to Bybee's idea since there is nothing under the umbrella of Derivation and Inflection; and it is, easily, known as Affix Morpheme (Prefix and Suffix but no infix).

According to his study, Shopen (1987: 165) mentioned an example of English and Chikasaw; as he mentioned that the verbs in English become negative by adding (not) to the Auxiliary verb and not to the main verb; unless the main verb would be one of the auxiliary verbs themselves (Be, Do, Have). Conversely, in the case of Chikasaw (Muskogean) in order to have negation the verb should undergo the following steps: (1) the verb should be preceded by the prefix of (ik-); (2) the next to the last vowel should be laryngealized. And, (3) the vowel of the word should be replaced by (o). Similarly, the case in the Kurdish language, there are no auxiliary verbs to help main verbs. All the negative versions of the words (verbs) should pass through some procedures: (1) no auxiliary verb is needed for negation. (2) Adding (Na-) as an affix to all kinds of verbs. And, (3) In case of compound words, the second word will take (-Na-); Examples: Xwendn (study) --- Naxwendn (no study), Yari and (play) --- Yari Nakrdn (no play).

\subsection{Syntactic Typology: Kurdish vs. English: Basic but Complicated Word Orders of both Languages}

Suppose you want to learn a language and you know the individual lexis; then, you want to join them logically by placing more important before fewer ones. But such result will not be a systematic and well-formed structure for few reasons: the choice of the words may differ between and in each language to convey the message, the form and structure of each word may change from one to another language; and finally, but the most important, the order of the words play a vital role to direct the message.

Since last few decades, Syntactic Typology played a crucial role in the area of linguistics (Croft 1995: 87; Moravcsik 2007) and helped the development of the language (Comrie, 2009). Moreover, Greenberg (1966), Jung (2001), Whaley (2008) and Moravcsik (2013) classified languages on the basis of the unmarked order of Nominal Subject (S), Verb (V) and Nominal Object (O), which resulted in six logically basic word orders: languages with basic orders are: SVO, SOV, VSO, VOS, OSV, or OVS. Moreover, in a study by Moravcsik (2013: 94) in an extensive sample consisting of 1228 languages; the result showed the enormous range of languages for each word order formation, such as:

S \& O \& V: 497 languages

$\mathrm{S} \& \mathrm{~V} \& \mathrm{O}: 435$ languages

$\mathrm{V} \& \mathrm{~S} \& \mathrm{O}: 85$ languages

$\mathrm{V} \& \mathrm{O} \& \mathrm{~S}: 26$ languages

$\mathrm{O} \& \mathrm{~V} \& \mathrm{~S}$ : 9 languages

$\mathrm{O} \& \mathrm{~S} \& \mathrm{~V}$ : 4 languages

Lacking a dominant order: 172 languages

The Table below examines the different syntactic patterns for both English and Kurdish only. In Kurdish there is no clear-cut definition for word order form, since the verb will 
take the boundary morpheme of the subject (pronoun) then different people utter the sentence in different syntactic forms and this caused a problem for foreign learners of the language; as they cannot handle the syntax due to the unspecified version of rules for sentence structure.

Table 2. English vs. Kurdish sentence structuring.

\begin{tabular}{llllll}
\hline & SVO & SOV & VSO & OVS & \multicolumn{1}{c}{ OSV } \\
\hline English & He ate the meal & X & X & X & X \\
Kurdish & Kuraka xwardi nanaka & Kuraka nanakai xward & Xwardi kuraka nanaka & Nanakai xward kuraka & Xwardi nanaka, Kuraka \\
& He ate the meal & He the meal ate & Ate he the meal & The meal ate he \\
\hline
\end{tabular}

Song (2011: 255) provided different word orders' of different languages; such as Korean (SOV), Thai (SVO), Welsh (VSO), Malagasy (VOS), Panare (OVS), and Nadeb (OSV). However, he did not mention any rule and word order for the Kurdish language. Due to Political, Economical, Religious, and Social factors Kurdistan could not able to create a specific language for itself; still, Kurdish people use Arabic and Latin alphabets. Besides, different regions and districts use different dialects and even accents. Nevertheless, none agree on a standard version of the language and each region believes its dialect is the pure one and everybody else should follow that one. For the above reasons, it is very hard to find studies on Kurdish Grammar and syntax that translated to other languages.

Grammatical Features of 2 Languages (Slobin. 2014:3), in compare with Kurdish:

Table 3. Word orders.

\begin{tabular}{llll}
\hline & English & Turkish & Kurdish \\
\hline basic word order & SVO & OSV & SVO, SOV, VSO, VOS, or OVS \\
the degree of word-order flexibility & Low & Very high & Very high \\
rich verbal inflexion (person/number) & No & Yes & Yes \\
case-inflectional morphology & No & Yes & Yes \\
nominal case / inflection & No & Always & Most of the Time \\
\hline
\end{tabular}

Some grammatical features of Kurdish compared with the English language: typological summary.

Table 4. Grammatical features.

\begin{tabular}{lll}
\hline & English & Kurdish \\
\hline Marking Type & Dependent & Dependent \\
Nominal Case Inflections & - & + \\
Grammatical morphology & Prefix, Suffix, Infix & Prefix and Suffix \\
Word-Order Variability & None & Very High \\
Pro-Drop & - & + \\
Top-/Subject- Prominent & Subject Prominent & Subject, Object, and \\
Classifiers & - & Verb Prominent \\
Motion Lexicalization & Satellite-framed & - \\
Grammaticized tense & + & Verb-Framed \\
Grammaticized Aspect & + & + \\
\hline
\end{tabular}

Both English tables are taken from (Slobin, 2014:17).

Linguists and grammarians, in general, are familiar with the idea that some languages are putting modifying or limiting elements before the modified or limited ones; in contrast, few others think the way around. Turkish in converse to Kurdish, an example of the former type, puts (adjectives before nouns, object before the verb, dependent genitive before governing noun, and adverbs before adjectives...etc). A language of the opposite type is Thai, similar to the Kurdish one, in which (adjectives follow the noun, object follows the verb, genitive follows governing noun). The majority of languages, English as an example, are not well marked in this respect. In English there are prepositions, and the noun object follows the verb. By contrast, English is similar to Turkish as the adjectives precede the noun.

Accordingly, Greenberg (1966: 85), the generator of the idea, explained three universal rules; however, none apply to the Kurdish language.

Universal 16:

In languages with dominant order VSO, an inflected auxiliary always precedes the main verb. However, in languages with dominant order SOV, an inflected auxiliary always follows the main verb. Conversely, none are applied on Kurdish since in the VSO structure there is no auxiliary to precede the main verb and in SOV structure the verb will not precede the auxiliary. The reason is quite clear since auxiliary verbs are absent in the Kurdish language.

Universal 17:

With overwhelmingly more than chance frequency, in languages with the dominant order of VSO adjective comes after the noun. In contrast, in the Kurdish language, the adjective will precede the noun in case of VSO word order. By contrast, the adjective will follow the noun in SOV.

Universal 18:

When the descriptive adjective precedes the noun, the demonstrative and the numeral, with overwhelmingly more than chance frequency, do likewise. Whilst, no frequency can be found in the Kurdish language to make the adjective and noun coherent.

Astonishingly, in few cases, the Kurdish language is more like German since they are from the same language family tree and background. Likewise, it has SVO in the main clause and SOV in the subordinate clause (Comrie, 2009); for example:

Zhnaka xwendi ktebaka. (Kurdish)

Die Frau las das Buch. (German)

The woman read the book.

Mn azanm ka zhnaka ktebakai xwend. (Kurdish) 
Ich weiß, dass die Frau das Buch gelesen. (German)

I know that the woman the book read $=(I$ know that the woman read the book)

Lehmann (1973, 1978) and Vennemann (1973, 1976) explained English language as an SVO dominant word order; in contrast, the Kurdish language carries no dominant word order and it may change from one district to another even due to the absence of internal development and/or contact with other neighboring languages like Arabic and Hawrami. Besides, Hawkin (1983: 90) illustrated the fact that in many (if not most) languages noun modifiers occur on both sides of the head noun. By contrast, the Kurdish language is quite different, since noun modifiers only occur in case of SVO; such cross-linguistics identification is accounted as a persistent issue in Linguistic typology (Stassen 1985).

The Kurdish language is not defined in terms of formal or semantic properties, as English does (Croft 1995: 88 and Song 2001: 10). On the other hand, a source by Haspelmath (2007: 119) explained the Kurdish case as semantic properties and not syntactic, since such language is known for its universal semantics. Indeed, some grammatical issues cannot be ignored easily and should be studied precisely, because some languages' word orders are based on a complex structure. The complexity of the language is defined as an independent language, as in the case of the Kurdish language. In addition, in the case of NP (Noun Phrase), the Kurdish language is rather different from English; in English usually, the Adjective comes before the Noun; but, in Kurdish is vice versa. The Examples that are shown below will clarify the issue:

a. The beautiful girl ............ Kcha jwanaka (girl - the - beautiful - the)

b. The lazy student ............. Xwendkara tamalaka (student - the - lazy - the)

c. A handsome teacher .......... Mamostayaki qoz (Teacher $-\mathrm{a}$ - handsome - a)

In the above examples, they will clarify that the articles in Kurdish cannot stand alone and they bind themselves to both adjective and noun. Moreover, in the English language only the noun can be definite or indefinite; in contrast, in Kurdish, both the adjective and the noun can be definite and indefinite through boundary morphemes.

Subsequently, Croft (2002: 195) explained some syntactic argumentations in generative analysis through some examples, as shown below, but in Kurdish, the argumentation is rather different and based on communication use rather than the generative rule. For instance:

a. Case making: He congratulated him/*he.

Kuraka pirozbayi krd leiy. Or Kuraka pirozbayi krd la kuraka.

(Which means both he and him can be used as an object)

b. Verb indexation: She likes $/ *$ like a cat.

Kchaka haz-i ba pshilaya.

We *likes/like a cat.

Ema haz-man ba pshilaya

(Which means Kurdish does not have $\{\mathrm{s}\}$ for third person singular; and, both (-i) and (-man) is used to identify the subject $\{$ which is she and we $\}$ ).

c. Imperative: Ø Take out the garbage.

Xolaka bba dare.

(In Kurdish we should identify the subject which is $\{$ you as.... [bba] is the verb for [you] and the root of the verb is $\{$ brdn $\}$.

Another difference could be found in their parameters; the Kurdish language is "Final Head", but English is "Initial head"; such as (Blue eye) in compare to (chaw shin \{eye blue $\}$ ). Such differences made the language (Kurdish) harder to digest; especially, for those who used English syntax as the main core of their studies. To follow up, between the cities of the same region in Kurdistan the syntax of the sentences are changing even if it is a slight one; for example:

Baran dabaret. (It rains, present simple) - (Sulaimani Region)

Yak baraneki dabaretn. (One rain is raining, present simple) - (Erbil Region)

\subsection{The Language's Universality or Uniqueness}

Different typologists study cross-linguistic variations in order to understand different languages that are spoken by a human; to understand the ratio wide ranges of languages should be studied; however, the paper will only deal with English and Kurdish language. As it is mentioned previously, both in Morphological structure and in syntactic one the two languages are different to some extent, to the furthest study; but still it does not mean that Kurdish is not accounted as the universal language, since Languages like Chinese, Japanese, and Turkish are not similar to English neither Morphologically nor Syntactically and still they are accounted as. For proof, Greenberg (1963: 73) said that the idea of language's non-universality is, in fact, a "tacitly implicational" and it is inferred by the "definitional characteristics of language". Moreover, Greenberg (1963: 74) and Jung (2001: 53) researched on several languages (almost 30 ) and classified different universal rules for a language. In Universal 1. Greenberg said "In declarative sentences with nominal subject and object, the dominant order is almost always one in which the subject precedes the object", in Universal 3. "Languages with dominant VSO order are always prepositional", and in Universal 4. "With overwhelmingly greater than chance frequency, language with normal SOV order are postpositional". Surprisingly, both universal 1. and 3. rules can be applied, even if not completely, in the Kurdish language. In Universal one; in declarative sentences, most of the nominal subjects will precede the nominal objects. In VSO order the prepositional structure is used. Finally, Nominal SOV order is mostly postpositional since frequency is a rare rule in Kurdish.

Rutherford (1984: 138) talked about SLA (Second Language Acquisition) and FLA (Foreign Language Acquisition) explanatory framework "though less often actually utilized" and he emphasized on the universality of each language that is spoken by human being even if it is a low rated (rare) spoken one; such as Chamicuro, Dumi, Ongoto, Liki, Tanima...etc. Even though none of the writers 
mentioned Kurdish language and this is the reason behind this research paper. Moreover, Indirect Measurement in morphology and Syntax are prime examples of productivity by counting hapax legomena (Baayen, 1992).

Undoubtedly, the Kurdish language is considered as one of the most difficult languages in the world to learn and comprehend; since there are no specific characteristics for the language and there is no standard language that foreigners of the language should rely on. Foreigners of the language should learn a specific dialect and accent, which is quite different from the others when they go to a specific region or even when they communicate with different people`s of different districts. Moreover, there are two main dialects which one is used in Turkey, Iran and Syria and its known as (Kurmanji) and another one is used in Kurdistan of Iraq and it is known as (Sorani); that is the reason that the Kurdish language is known as the double standard dialects of the language. By contrast, the Kurdish language does not have a standard way of writing (Alphabets) and this made the language much simpler to understand; since both Arabic and Latin Alphabets are using in Formal (Academic) and Informal writings. To be more precise, due to political and economic factors and geographical reasons the Kurdish scholars could not agree on a specific Kurdish Alphabet. Beside all, there is no academic centre, an institution, or a public organization to teach foreigners the Kurdish language. Even though, there are many centres to learn other languages like Arabic, Spanish, French, English, Chinese...etc, but the absence of Kurdish learning centre made the language frozen and fossilized, and you can see no development in the language.

\section{Conclusion}

Since a short assignment is not the place for a detailed presentation of the broad field of linguistic typology; only a few examples of current issues and recent developments in Morphological and Syntactic typology have been given and provided. But, it is really an amazing fact that how human language basically serves the purpose of human communication in regard to all those differences that can be seen between two languages from their phonemes to their sentences. Furthermore, all the languages around the world that are spoken have a common nature; and revealing such commonness is the highest objective of language and linguistic studies. Therefore, linguistic typology is a challenge to gain this purpose through a systematic analysis of language diversity.

Through the paper, it can be concluded that how English is a dynamic language and the state is non-progressive like Chamorrow. But, how Kurdish is a closure language and the state is imperfective like Russian language (Shopen, 1987). Needless to say, reviews like that will, in fact, demand more than a chapter, if not a book; as the relation between language universals and FLA/SLA was clearly explained very early by linguists/typologist in modern linguistic typology.

The paper tried to answer several research questions; as the different parameters of both English and Kurdish were shown and illustrated with examples. Later, the effect of intonation was described in Kurdish sentences and how the intonation in Kurdish takes the place of prepositions in English. Lately, both languages ' word orders were explained precisely. Finally, the uniqueness of Kurdish language was clarified; however, still, it is accounted as a universal language due to a spoken group of people, even though it undergoes many rare rules. As a result, the best way to learn the Kurdish language is to communicate with the native language people to understand the parameters. Since communication helps the learners to cope with the language much easier.

In a nutshell, such differences between both languages may appear due to some internal and external factors:

a. Our innate gift supports such structure (Or it is more like inherited); however, no direct evidence can be found, (Kurdish people).

b. Each structure functions in a specific language, (The differences can be seen in English and Kurdish).

c. Having different structures in each language helps the acquisition of children, (Some structures cannot be acquired by children easily); (Age, Gender, Culture, and Society may have an indirect effect on the issue too).

d. One structure can be processed easily but not the other ones, (It depends on Ethnolinguistics, Neurolinguistic, Sociolinguistics and Psycholinguistics).

\section{References}

[1] Baayen, H. (1992). Quantitative aspects of morphological productivity. In Geert Booij \& Jaap van Marle (eds.), Yearbook of Morphology 1991, Dordrecht: Kluwer, 109-149.

[2] Bybee, J. (1985). Morphology. Benjamins: Amsterdam.

[3] Bybee, J. (1997). Semantic aspects of morphological typology. John Benjamins: Philadelphia, USA.

[4] Caffarel, A., Martin, J. R., and Matthiessen, C. M. I. M. (eds.) (2004). Language Typology: A Functional Perspective. Benjamins: Amsterdam.

[5] Comrie, B. (1981). Language Universals and Linguistic Typology. Blackwell: Oxford.

[6] Comrie, B. (2009). Language universals and linguistic typology: syntax and morphology. Peking university press: China.

[7] Croft, W. (1990). Typology and Universals (2 ${ }^{\text {nd }}$ ed.). Cambridge University Press: UK.

[8] Croft, W. (1995). "Modern Syntactic Typology", in Shibatani, Masayoshi, Theodora Bynon (eds.) (1995), Approaches to Language Typology, Oxford: Oxford University Press, pp. 85145 .

[9] Croft, W. (2002). Typology and Universals. Cambridge University Press: UK.

[10] Croft, W. (2003). Typology and Universals. Cambridge University Press: UK. 
[11] Dixon, R. M. W. (1997). The Rise and Fall of Languages. Cambridge University Press: UK.

[12] Dixon, R. M. W. (2012). Basic Linguistic Theory 1. Oxford University Press: New York.

[13] Dixon, R. M. W. (2012). Basic Linguistic Theory 2. Oxford University Press: New York

[14] Dixon, R. M. W. (2012). Basic Linguistic Theory 3. Oxford University Press: New York.

[15] Fortescue, M. (1984). West Greenlandic. Croom Helm: London.

[16] Goldberg, A. E. (1995). Constructions: A Construction Grammar Approach to Argument Structure. The University of Chicago Press: Chicago, USA.

[17] Greenberg, J. H. (1963). "Some Universals of Grammar with Particular Reference to the Order of Meaningful Elements", In Joseph H. Greenberg (ed.). Universals of Language. London: MIT Press, pp. 73-75.

[18] Greenberg, J. H. (1966). "Some Universals of Grammar with Particular Reference to the Order of Meaningful Elements", in Greenberg, Joseph H. (ed.) (1966), Universals of Language (2nd edition), Cambridge: MIT, pp. 73-113.

[19] Greenberg, J. H. (1963). Some Universals of Grammar with Particular References to the Order of Meaningful Elements, in J. H. Greenberg (ed.) (1963).

[20] Greenberg, J. H. (1963). Universals of Language. MIT Press: Cambridge, Massa chutes, USA.

[21] Haegeman, L. (1994). Introduction to Government and Binding Theory. Blackwell: OUP, UK.

[22] Haiman, J. (1980). The Iconicity of Grammar: Isomorphism and Motivation, Language, vol. 58, pp. 515-540.

[23] Haiman, J. (1983). Iconic and Economic Motivation, Language, vol. 59 (4), pp. 781-819.

[24] Halliday, M. A. K. (2001). Language as Social Semiotic: The Social Interpretation of Language and Meaning. Edward Arnold: China.

[25] Halliday, M. A. K. (2003). On Language and Linguistics. Continuum: New York, USA.

[26] Halliday, M. A. K. (2004). An Introduction to Functional Grammar ( $3^{\text {rd }}$ ed.). Oxford University Press: New York, USA.

[27] Halliday, M. A. K. (2005). Computational and Quantitative Studies. Continuum: New York, USA.

[28] Halliday, M. A. K. (2006). Studies in the Chinese language. Continuum: New York, USA.

[29] Halliday, M. A. K. (2007). Language and Education. Continuum: New York, USA.

[30] Halliday, M. A. K. (2014). Halliday`s Introduction to Functional Grammar ( $4^{\text {th }}$ ed.). Routledge: USA.

[31] Halliday, M. A. K. and Hasan, R. (1989). Language, Context, and Text: Aspects of Language in a Social-Semiotic Perspective. Oxford University Press: UK.

[32] Halliday, M. A. K. and Webster, J. J. (2009). Continuum
Companion to Systemic Functional Linguistics. Continuum: London.

[33] Haspelmath, M. (2007). Pre-established Categories Don't Exist Consequences for Language Description and Typology, Linguistic Typology, Vol. 11 (1), pp. 119-132.

[34] Hawkins, J. (1983). Word Order Universals. Quantitative Analyses of Linguistic Structure, New York: Academic Press. Stassen, Leon (1985), Comparison and Universal Grammar. Blackwell: Oxford.

[35] Jung, S. (2001). Linguistic Typology: Morphology and Syntax. Pearson: UK.

[36] Lehmann, W. (1973). A Structural Principle and its Implications, Language, Vol. 49 (1), pp. 42-66.

[37] Lehmann, W. (1978). "The Great Underlying Ground-plans", in Lehmann, Winfred P. (ed.) (1978), Syntactic Typology: Studies in the Phenomenology of Language, University of Texas Press: Austin, pp. 3-55.

[38] Li, C. N. and S. A. Thompson (1981). Mandarin Chinese: A functional reference grammar. University of California Press: Berkeley.

[39] Lyovin, A. V. (1997). An introduction to the languages of the world. Oxford University Press: Oxford.

[40] Martin, J. R. (1992). English Text: System and Structure. John Benjamins: Philadelphia and Amsterdam.

[41] Martin, J. R. and White, P. R. R. (2005). The Language of Evaluation: Appraisal in English. Palgrave: New York, USA.

[42] Moravcsik, E. (2007). What is Universal about Typology?, Linguistic Typology, Vol. 11 (1), pp. 27-41.

[43] Moravcsik, E. (2013). Introducing Language Typology. Cambridge University Press: UK.

[44] Payne, T. E. (1997). Describing morphosyntax: A guide for field linguists. Cambridge University Press: Cambridge.

[45] Plank, F. (2007). Preface, Linguistic Typology, Vol. 11 (1), pp. $1-3$.

[46] Poppe, N. (1960). Buriat Grammar. Bloomington: Indiana University.

[47] Ruqaiya, H. (2000). Semantic Variation: Meaning in Society and in Sociolinguistics. Harville Press: London.

[48] Russell, B. (1948). Human Knowledge: its Scope and Limits. New York: Simon \&Schuster.

[49] Rutherford, W. E. (1984). Description and Explanation of Inter-language Syntax: State of the Art, LL, Vol. (34), pp. 127155 .

[50] Sapir, E. (1921). Language. Harcourt Brace and World: New York.

[51] Shopen, T. (1987). Language Typology and Syntactic Description: Grammatical categories and the Lexicon. Cambridge University Press: Cambridge, UK.

[52] Shopen, T. (2007). Language Typology and Syntactic Description: Clause Structure. Cambridge University Press: Cambridge, UK. 
[53] Slobin, D. (2004). Issues of Linguistic Typology in the Study of Sign Language Development of Deaf Children. B. Schick, M. Marschark, \& P. E. Siple (Eds.), Sign Language Development of Deaf Children: Where Have We Been, and Where Are We Going? Oxford University Press: Oxford.

[54] Song, J. (2001). Linguistic Typology: Morphology and Syntax. Pearson: Harlow.

[55] Song, J. J. (2011). The Oxford Handbook of Linguistic Typology. Oxford University Press: New York, USA.

[56] Vennemann, T. (1973). "Explanation in Syntax", in Kimball, John P. (ed.), Syntax and Semantics, New York: Seminar, pp. $1-50$.
[57] Vennemann, T. (1976). "Categorial Grammar and the Order of Meaningful Elements", in Juilland, Alphonse (ed.) (1976), Linguistic studies offered to Joseph Greenberg on the occasion of his 60th birthday, Saratoga, CA: Anma Libri, pp. 615-634.

[58] Wang, Y. and Zhou, Y. (2014). A Functional Study of EventExistentials in Modern Chinese, Functional Linguistics, vol. 1 (7), pp. 1-17.

[59] Whaley, L. (2008). Introduction to Typology: The Unity and Diversity of Language. Sage Publication: California, USA. 